\title{
Brain stimulation used as biofeedback in neuronal activation of the temporal lobe area in autistic children
}

\author{
Estimulação cerebral usada como biofeedback na ativação neural do lobo temporal em \\ crianças autistas \\ Vernon Furtado da Silva', Mauricio Rocha Calomeni², Rodolfo Alkmim Moreira Nunes' ${ }^{1}$, Carlos Elias \\ Pimentel', Gabriela Paes Martins' ${ }^{1}$ Patrícia da Cruz Araruna Oliveira3 ${ }^{3}$ Patrícia Bagno Silva', Alair Pedro \\ Ribeiro de Souza e Silva ${ }^{2}$
}

\begin{abstract}
This study focused upon the functional capacity of mirror neurons in autistic children. 30 individuals, 10 carriers of the autistic syndrome (GCA), 10 with intellectual impairments (GDI), and 10 non-autistics (GCN) had registered eletroencephalogram from the brain area theoretically related to mirror neurons. Data collection procedure occurred prior to brain stimulation and after the stimulation session. During the second session, participants had to alternately process figures evoking neutral, happy, and/or sorrowful feelings. Results proved that, for all groups, the stimulation process in fact produced additional activation in the neural area under study. The level of activation was related to the format of emotional stimuli and the likelihood of boosting such stimuli. Since the increase of activation occurred in a model similar to the one observed for the control group, we may suggest that the difficulty people with autism have at expressing emotions is not due to nonexistence of mirror neurons.
\end{abstract}

Keywords: autistic disorder; mirror neurons; emotions.

\section{RESUMO}

O estudo verificou a capacidade funcional dos neurônios-espelho em crianças autistas. 30 indivíduos, sendo 10 portadores da síndrome autista (GCA), 10 com deficiência intelectual (GDI), e 10 não-autistas (GCN) tiveram registrado o eletroencefalograma da área do cérebro relacionada teoricamente com os neurônios espelho. O procedimento de coleta de dados ocorreu antes e após uma sessão de estimulação cerebral. Durante a segunda coleta de dados, os participantes tiveram de processar alternadamente figuras evocando sentimentos neutros, felizes e tristes. Os resultados provaram que, para todos os grupos, o processo de estimulação de fato produziu ativação adicional na área neural em estudo. O nível de ativação foi relacionada com o formato dos estímulos emocionais. Uma vez que o aumento da ativação ocorreu em um modelo semelhante ao observado para o grupo controle, pode-se sugerir que as pessoas com autismo têm dificuldade em expressar emoções não devido à inexistência de neurônios-espelho.

Palavras-chave: transtorno autístico; neurônios-espelho; emoções.

Autism spectrum disorder (ASD) is a pervasive neurodevelopmental disorder characterized by dysfunctional socialization and communication, with the emergence of stereotyped and repeated behavior ${ }^{1}$, by social symptoms and atypicalities in elementary aspects of perception, as in the case of visual processing of emotional and neutral facial expressions $^{2}$. For some researchers, it may be a consequence of the poor neural connectivity in ASD, particularly to and within prefrontal and parietal regions ${ }^{3}$.
Thus, it is generally accepted that individuals with some form of ASD display at least some impairment in recognizing emotions through facial expressions ${ }^{4}$, although there are a host of inconsistent results ${ }^{5}$. However, the automatic mirroring of affective gestures and expressions is also considerably weaker in infants with $\mathrm{ASD}^{6}$ and the differences in emotion processing between typically developing individuals and their peers with ASD are also observable at a neural level'.

\footnotetext{
'Universidade do Estado do Rio de Janeiro, Laboratório de Esportes, Rio de Janeiro RJ, Brasil;

${ }^{2}$ Universidade Federal do Rio de Janeiro, Laboratório de Mapeamento Cerebral e Integração Sensório Motora do Instituto de Neuropsiquiatria, Rio de Janeiro RJ, Brasil; ${ }^{3}$ Centro Universitário de João Pessoa, João Pessoa PB, Brasil.

Correspondence: Mauricio Rocha Calomeni; Rua Benta Pereira, 237 / apt 903; 28035-290 Campos dos Goytacazes RJ, Brasil; E-mail:mauriciocalomeni@gmail.com Conflict of interest: There is no conflict of interest to declare.
}

Received 25 November 2015; Accepted 23 May 2016. 
It has been postulated and proven by neuroscientists that the inability of children with autism to relate to people and life situations in the ordinary way depends on a lack of a normally functioning mirror neuron system ${ }^{7}$. So much so that according to Palau-Baduell et al. ${ }^{8}$, currently, the hypothesis of a dysfunction in the mirror neuron system in individuals with autism has received significant attention from several researchers.

Thus, the aim of the study was to investigate reactivity in the mirror neuron system to emotional stimuli in individuals with autism and their peers who do not have autism and do not have mental illness, and testing the hypothesis that these groups can be stimulated through biofeedback.

\section{METHOD}

Subjects were randomly chosen from three centers specializing in treating children with special needs and that are prepared to deal with children with autism and other children with neural disorders not associated to autism. These centers also maintain, as a treatment strategy, regular contact with all the children and their caregivers, being able to provide historical record about the progression of the disease of each child, which facilitated all the research phases. There was also a control group whose participants were children studying in schools at the vicinity of the treatment centers. The participants were identified from indication of the responsible professionals who served them in their centers and schools, and those responsible for the participants were informed and they gave permission by signing the consent form.

The sample was composed of 30 children, 10 of them being from groups clinically diagnosed as suffering from autism spectrum disorder (GCA). Ten other children, in spite of being clinically diagnosed as having intellectual impairment also had enough capability for interacting and executing all the tasks related to the research (GDI). The 10 remaining children composed the group without diagnosis of any type and/or level of psychophysiological impairment and who have normal scholastic development (GCN).

To be included in the control group, the children chosen in schools had to have cognitive development compatible with their chronological age, with a good educational development and without problems of social interaction, also as certified by their teachers. For the group with children with autism, they had a clinical diagnosis of autism (DSM-5) but in a degree that allows the level of interaction necessary for the methodology of this study, while those in the DI group had been diagnosed with intellectual impairment not linked to autism, which clearly compromised their activities of daily living (ADLs). Cases that did not strictly meet the inclusion criteria were not included in any of the groups. The study was approved by the Human Research Ethics Committee of the Institutes for Higher Learning of CENSA (ISECENSA) under protocol no. 296.193.
For the recordings of alpha wave (EEG), the instrument selected was Pocomp + by Touch Technology. The device has its own grounding to eliminate any possibility of electrical interference during signal capture and has been highly effective in neuroscience research ${ }^{9,10}$. Electrode placement for EEG recording complied with the 10-20 system of the Brazilian Society of Clinical Neurophysiology.

The electrodes were positioned on the temporal lobe, site of the amygdala, a neural structure related to the emission of a response to emotionally important stimuli, whether the context is pleasant or unpleasant ${ }^{11}$. Specifically, the point selected for the recording was $\mathrm{T} 6-\mathrm{A} 1+\mathrm{A} 2$, due to the relationship between this point and the Wernicke area, a general interpretive region associated to knowledge and intelligence ${ }^{12}$. Since it is located in the right hemisphere, this point may reflect more specific responses because this hemisphere is more effective than the left in terms of recognizing stimuli that demand emotional responses.

The pre-intervention data collection consisted of recording the electroencephalographic (EEG) signals of the study subjects individually, in a duly prepared room. A baseline pattern of these neurons was recorded in a state of general physical rest while controlling other stimuli such as room temperature, external noise, and ambient light that could mask response specificity. Data collection was considered neutral phase 1 for 2 min for each individual in each group. A cutoff point from earlier recordings was always observed at the beginning of the 2-min period.

A second verification in this pre-stimulation phase occurred during presentation of pictures showing children's faces expressing emotions. The recording (EEG) was made at the same cortical point of earlier recordings. The sampling period of the figures and recordings (concomitantly) was 4 min, 2 min corresponding for the sample of happy pictures and $2 \mathrm{~min}$ for sad faces. Four figures were shown to each child in the same sequence, 2 depicting happiness and 2 sadness. Each figure was observed by a period of $1 \mathrm{~min}$ in which was asked the recognition of the expression (happiness or sadness); manipulation of the figures was also permitted by subjects if they wanted to.

After the collection period, the groups underwent the intervention phase characterized by a non-invasive, painless, and non-stressful activity; all subjects, including members of the group with autism, accepted the placement of auditory/visual components inherent to stimulation without protest, and two occupational therapists helped entertain the children during this and other data collection phases. Brain stimulation was made through application of strobe lights and binaural beats in a frequency of 8 to 12 hertz $(\mathrm{Hz})$ and in an intensity adjusted to the comfort of each subject.

This occurred over a short time period, in the morning or afternoon, so the children from the three groups could also alternate the corresponding pre-stimulation period. Thus, around half of each group performed the 
study tasks first in the morning and then in the afternoon, while the other half executed them in the reverse order. In this phase of the intervention, brain stimulation was applied to each member of each group individually. The neural activation period aimed at hemispheric equalization in the participants was 10 min for each participant. The next step of the intervention involved collection of post-stimulation data, an identical procedure to pre-stimulation data collection, even as regards base data (neutral phase 2). Similarly, all the children took part in this phase.

Data of three recordings at point T6 were analyzed using descriptive and inferential statistics. Descriptive statistics analyzed mean cortical waves in the different groups at different moments, in addition to standard deviations and minimum and maximum scores. For inferential analysis between groups, the data were $100 \%$ normalized and how much each individual in the group oscillated (in \%) from pre- to post-test was also taken. After this normalization, one-way ANOVA was applied to determine if the percent variations between pre- and post-stimulation produced statistically significant indexes in the groups. Afterwards, the Tukey test was applied as supplementary verification seeking to construe the specificity of evidence found. For the purpose of standardization, we studied the need to transform or not the activation level scores into $\mathrm{Z}$ scores. At any rate, the reference point for the test of hypotheses of the study was alpha $\leq 0.05$. Spurious data were not used in any of the analyses.

\section{RESULTS}

The first set of data presented in Table were the alpha frequency band data for the group with autism, the DI group, and the control group, comparing the data obtained at preand post-brain stimulation collections.

The data exhibit parametric characteristics, and the observations regarding the central tendency of brain activation in each group were made using the arithmetic mean of neural activity at point T6. The pattern exhibited by the groups before brain stimulation showed that the groups with autism and DI have had a very similar neural activity. Nevertheless, the control group showed a different pattern, with relatively low neural activity when compared with the other two groups. Another interesting observation is the fact that in this prestimulation phase, the neural activity of the groups was much lower in response to neutral stimulus, compared to activation in response to the two affective stimuli (happiness and sadness). Furthermore, individuals with autism and the control group seem to activate more neurons when processing images that depict feelings of happiness, whereas the group composed of intellectually impaired subjects exhibited greater activation during the processing of images that tend to transmit feelings of sadness. Overall variations in neural activation with respect to analysis of responses to expressions of happiness and/or sadness were minimal for all the groups.

Cortical alpha frequency readings after brain stimulation revealed interesting variations when compared to pre-stimulation recordings, characterized primarily by increments in activation that occurred at almost all the recordings, except in the group with autism, which, after stimulation, showed reduced neural activity in processing images that conveyed happiness. With regard to readings taken after exposure to images depicting sadness, all three groups also exhibited high activation patterns, compared to the pre-stimulation phase. The group with autism, for example, during processing of neutral stimuli exhibited increased activity during poststimulation assessment. When they were exposed to images depicting happiness, albeit post-stimulation, individuals

Table. Descriptive record of neural activity in groups GCN, GCA, GDI, pre and post photic and auditory stimulation, during processing of neutral stimuli, and images that depict feelings of happiness and sadness.

\begin{tabular}{|c|c|c|c|c|c|c|c|c|c|c|c|c|c|c|c|c|c|c|}
\hline \multirow{3}{*}{ Variable } & \multicolumn{6}{|c|}{ Autistic group } & \multicolumn{6}{|c|}{ Control group } & \multicolumn{6}{|c|}{ DI group } \\
\hline & \multicolumn{2}{|c|}{ Neutral } & \multicolumn{2}{|c|}{ Happiness } & \multicolumn{2}{|c|}{ Sadness } & \multicolumn{2}{|c|}{ Neutral } & \multicolumn{2}{|c|}{ Happiness } & \multicolumn{2}{|c|}{ Sadness } & \multicolumn{2}{|c|}{ Neutral } & \multicolumn{2}{|c|}{ Happiness } & \multicolumn{2}{|c|}{ Sadness } \\
\hline & M & $\mathrm{CV}$ & $M$ & $\mathrm{CV}$ & $M$ & $\mathrm{CV}$ & $M$ & $\mathrm{CV}$ & $M$ & $\mathrm{CV}$ & $M$ & $\mathrm{CV}$ & $M$ & $\mathrm{CV}$ & $M$ & CV & $M$ & $\mathrm{CV}$ \\
\hline \multicolumn{19}{|c|}{ Pre-Stimulation } \\
\hline Minimum & 1.75 & 0.36 & 3.34 & 0.40 & 2.39 & 0.38 & 1.05 & 0.56 & 1.51 & 0.43 & 1.37 & 0.38 & 2.81 & 0.40 & 3.96 & 0.38 & 4.12 & 0.38 \\
\hline Median & 3.81 & 0.48 & 13.8 & 0.54 & 11.1 & 0.48 & 2.64 & 1.81 & 3.46 & 1.76 & 4.13 & 2.70 & 16.4 & 0.46 & 21.4 & 0.44 & 24.6 & 0.49 \\
\hline Maximum & 38.6 & 1.06 & 38.2 & 0.89 & 40.7 & 0.82 & 12.4 & 8.72 & 15.2 & 14.9 & 13.0 & 10.4 & 25.8 & 0.50 & 41.5 & 0.66 & 42.3 & 0.80 \\
\hline Mean & 14.9 & 0.53 & 16.6 & 0.59 & 16.4 & 0.55 & 4.68 & 3.23 & 5.92 & 4.72 & 5.65 & 4.05 & 15.3 & 0.45 & 21.9 & 0.47 & 23.1 & 0.53 \\
\hline $\mathrm{SD}$ & 16.7 & 0.24 & 15.5 & 0.20 & 16.4 & 0.17 & 5.28 & 3.83 & 6.28 & 6.90 & 5.12 & 4.70 & 8.72 & 0.03 & 12.6 & 0.09 & 12.8 & 0.15 \\
\hline \multicolumn{19}{|c|}{ Post-Stimulation } \\
\hline Minimum & 5.00 & 0.47 & 2.81 & 0.42 & 4.73 & 0.43 & 2.96 & 1.10 & 3.61 & 1.01 & 4.12 & 1.32 & 4.51 & 0.39 & 4.09 & 0.38 & 4.90 & 0.38 \\
\hline Median & 7.06 & 1.04 & 11.4 & 0.86 & 11.3 & 0.91 & 10.9 & 1.27 & 9.26 & 1.65 & 10.2 & 1.82 & 22.2 & 0.44 & 23.2 & 0.41 & 23.0 & 0.44 \\
\hline Maximum & 47.8 & 2.04 & 46.0 & 2.00 & 52.5 & 1.65 & 21.5 & 8.07 & 16.5 & 3.83 & 25.7 & 2.32 & 43.1 & 0.52 & 42.8 & 0.54 & 43.6 & 0.54 \\
\hline Mean & 16.2 & 1.05 & 15.7 & 0.89 & 19.2 & 1.01 & 11.5 & 2.93 & 9.66 & 2.04 & 12.6 & 1.82 & 22.7 & 0.44 & 23.9 & 0.42 & 24.3 & 0.44 \\
\hline SD & 16.7 & 0.51 & 14.7 & 0.54 & 18.2 & 0.46 & 7.87 & 3.43 & 6.43 & 1.23 & 10.4 & 0.40 & 14.0 & 0.044 & 15.3 & 0.053 & 15.1 & 0.06 \\
\hline
\end{tabular}

M: mean activation, in millivolts $(\mathrm{mV}$ ) of neurons from the T6 area during electroencephalographic collection; CV: coefficient of variation in neuronal activation from the T6 area during electroencephalographic collection; SD: standard deviation. 
with autism exhibited decreased neural activity. However, during the presentation of images of sad faces after stimulation, neural activity was increased in this group.

What do the aforementioned values and their variations express in terms of the competency of people with autism in the perception/action relationship, considering data gathered at pre- and post-stimulation? As reported by Calomeni et al. ${ }^{10}$, the percentage values of a series of cortical activation data, obtained by activation and/or deactivation, express a quantitative relationship of neurons mobilized during mental processing activities, whereas the coefficient of variation (CV) indicates the qualitative relationship of this mobilization. Given the above results, it can be concluded that during the processing of neutral stimuli and sad faces, the group with autism showed a quantitative (represented by a rise in mean activation), but not qualitative increase, as evidenced by the higher coefficient of variation (CV). During processing of the figure showing happiness, this group exhibited a reduction in neural activity and an increase in post-stimulation CV.

The control group data, in turn, revealed very different values and variations from both the groups with autism and DI, given that neural activity increased in all three experimental situations after stimulation. However, just as important as this quantitative increase was the concomitant reduction in variation coefficients, representing a qualitative change in the processing of figures and in the neutral processing condition.

Finally, individuals with intellectual impairment (DI group) also showed a quantitative rise in neural activation after stimulation. In relation to the qualitative aspect, this group was more evenly balanced at pre- and post-stimulation than the other two groups. However, the difference was very slight, showing a tendency to qualitative improvement, expressed by the direct reduction in the coefficient of variation at each processing moment. Figure 1 illustrates all descriptive analyses presented up to this point.

Intergroup and intragroup inferential analyses were conducted with normalized data (Z score) using the ANOVA test. Results of intergroup comparisons revealed no statistically significant difference, that is, in all situations, the value obtained was $\mathrm{p}>0.05$, thereby eliminating the need for supplementary testing.

This finding, in accordance with the theoretical predictions of the study, was very likely to occur. This is because the phenomenon targeted was the possibility that certain neurons in the temporal lobe, confirmed by earlier research as being associated to mechanisms of human emotion, using an electrical stimulation procedure, could be boosted even in individuals with autism who normally experience emotional difficulties in their daily lives.

\section{DISCUSSION}

Calomeni et al. ${ }^{10}$ proved that increased motor function was more related to a lower dispersion of activation (qualitative increase) in the cortical motor area.
In a previous study, Palau-Baduell et al. ${ }^{8}$ claimed that the activity of mirror neurons in humans has been investigated by analyzing reactivity in the EEG. Therefore, we recorded
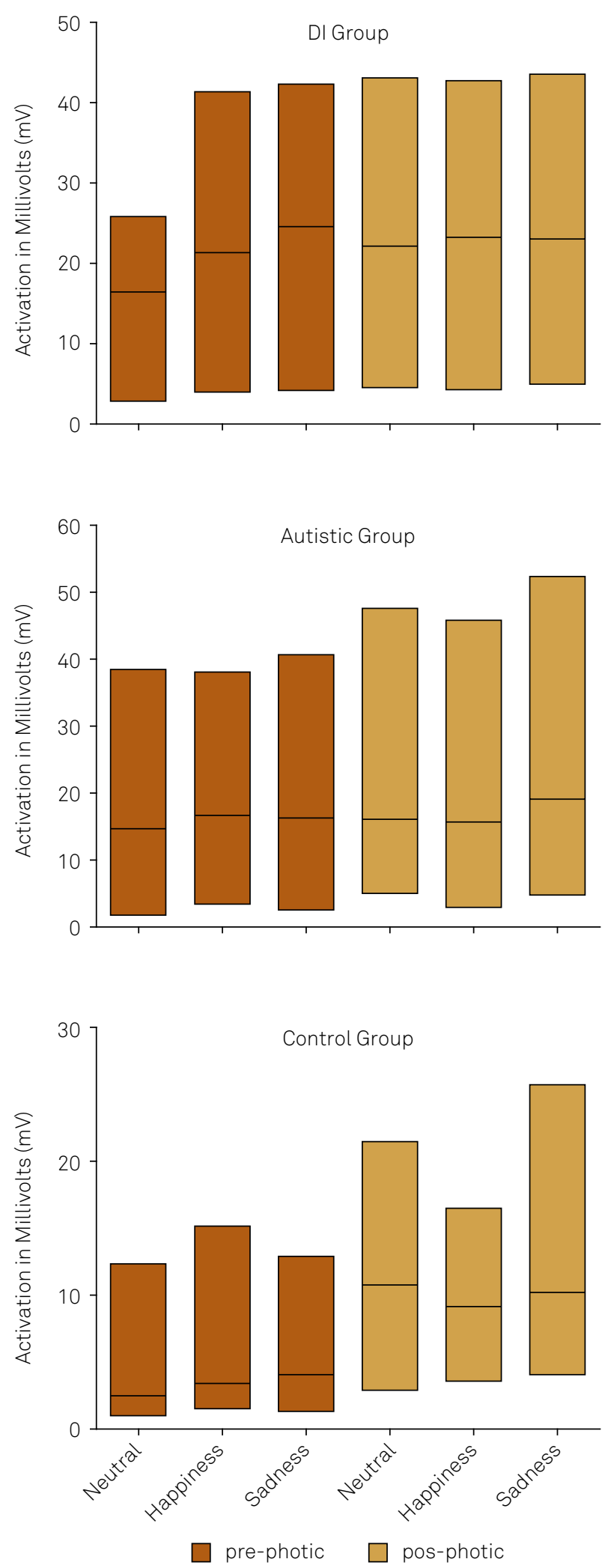

Figure. Plotting between pre- and post-photic and auditory stimulation in the GCN, GCA, GDI groups. The midline indicates the arithmetic mean in $\mathrm{mV}$ of the neural activity at point T6 in the different processing situations assessed. The solid area corresponds to pre-stimulation assessment. 
that even before stimulation, neurons from the cortical area assessed by EEG recordings reacted in a particular way to different processing situations, most likely based on previous emotional experiences.

After being boosted by photic/auditory stimulation, the same neurons exhibited increased reactivity, as evidenced by the recordings obtained for all the groups. Another interesting fact is that before stimulation, EEG recordings demonstrated the same response pattern for all three groups, with the processing of the neutral stimulation showing the lowest neural activity. Despite this pattern, the control group registered the lowest neural activity and the highest dispersion during this activity. This may have occurred due to the nature of the stimulus itself, which, for the individuals of this group, may have evoked more "dispersed" feelings, which are less intense compared with those experienced by members of the other two groups. This dispersion can be explained as a function of the conceptual notions implicit in the theory of mind and empathy ${ }^{13}$, and the fact that human mirror neurons are related to higher-order brain processes, such as learning by imitation, language, skills of theory of mind, empathy, perceived intentions and social cognition ${ }^{8}$.

Studies such as those by Kilts et al. ${ }^{14}$ have demonstrated differential patterns of brain activation in response to dynamic versus static facial emotion stimuli. Moreover, Molnar-Szakacs et al. ${ }^{6}$ described neuroimaging studies that investigated the imitation of emotional facial expressions, and showed that children with autism have virtually no activity in mirror neurons compared with children in the control group. However, studies with functional magnetic resonance imaging ( fMRI) suggest that a much larger network of brain areas show mirror properties in humans than previously thought ${ }^{15}$.

The results presented suggest that the mirror neurons of these individuals are present in the cortical area measured, and are reactive to emotional processing situations. In other words, children with autism smile or feel sad internally (emotional experience), but do not manifest these feelings externally (emotional expression). That is, they do not have suitable cognitive ability to process environmental and internal data in a harmonious and effective structuring ${ }^{16}$. Implicit to this version of the existence of central incoherence in the brain of a person with autism, there is also the possibility that such incoherence may have originated from the impairment of executive functions ${ }^{13}$, and that if mirror neurons are actually involved in the interpretation of complex intentions, then the interruption of neural circuitry could explain the classic symptoms of autism and their lack of social skills ${ }^{17}$.

Based on neurological theory, which explains the relationships between body, mind, and environment, quantitative resemblance is based on the possibility that brain stimulation enhanced the neural drive of group members. Such fact is supported by the Hebbian theory in which simultaneous activation of cells leads to pronounced increases in synaptic strength between those cells ${ }^{15}$. As a consequence, this restructuring could have resulted in enhanced interpretation of the stimuli that people with autism had to process.

A plausible conjecture regarding structural brain changes in autism is mediated with respect to the disproportional and elevated growth of this organ during the initial phase of development in a child with autism. Although a number of brain regions can be cited as exhibiting growth discrepancy, in both white and gray matter, primarily the frontal lobes, more gray matter tends to exist ${ }^{18}$, a development pattern quite different from that commonly observed in children without autism. This partially explains a possible control difficulty in the brain of a person with autism with respect to containing the growth of undesirable synapses ${ }^{19}$, or on the other hand, preventing the normal development of neural connections necessary for the organized and effective flow of the central information processing system, which represents a natural association with the matching perception and memory implicit in all normal human behaviors.

More recently, Acharya and Shukla ${ }^{15}$ presented the idea that autism is characterized by two neuropsychiatric abnormalities. The first is about defects in the social-cognitive domain, which presents as mental aloneness, a lack of contact with the external world, and lack of empathy. The second is sensorimotor defects, such as temper tantrums, head banging, and some form of repetitive rituals. All these are now suggested to be caused by some anomaly in mirror neuron development. Also, the other hypothesis presented by Zangwill ${ }^{20}$, based on other authors' works, is the proposed hypothesis of the which other-mind thought creates stress, inhibiting thinking in those terms. On this view, there is no cognitive shortfall as there is on the mind-blindness hypothesis. Nevertheless, whatever the explanation, those with autism systematically do worse in similar circumstances in attributing emotional states to other minds.

In conclusion, brain stimulation produced some type of change in synaptic activities in all the groups, and possible neuroplastic alterations, at least of a temporary nature. This type of change has been reported in a wide variety of studies $^{10,21}$. The analyses also suggest that in all the groups studied, the cortical point with respect to the location of neurons that react to emotional stimuli responded to stimulations that depict emotional responses. Furthermore, due to the differences (increased) in activation recorded in these neurons after stimulation, it can be concluded, with some certainty, that they can be activated, provided that adequate procedures are used. We believe that mirror neurons do in fact exist in individuals with autism and tend to respond when such individuals are presented with emotional stimuli. Thus, the absence of compatible emotional expression and harmony commonly observed in interactions between individuals with autism and others is most likely unrelated to the activation of neurons or not in the cortical area investigated in this study. 


\section{References}

1. Corradi-Dell'Acqua C, Schwartz S, Meaux E, Hubert B, Vuilleumier $P$, Deruelle C. Neural responses to emotional expression information in high- and low-spatial frequency in autism: evidence for a cortical dysfunction. Front Hum Neurosci. 2014;8:189. doi:10.3389/fnhum.2014.00189

2. Gaigg SB. The interplay between emotion and cognition in autism spectrum disorder: implications for developmental theory. Front Integr Neurosci. 2012;6:113. doi:10.3389/fnint.2012.00113

3. Wicker B, Fonlupt P, Hubert B, Tardif C, Gepner B, Deruelle C. Abnormal cerebral effective connectivity during explicit emotional processing in adults with autism spectrum disorder. Soc Cogn Affect Neurosci. 2008;3(2):135-43. doi:10.1093/scan/nsn007

4. Harms MB, Martin A, Wallace GL. Facial emotion recognition in autism spectrum disorders: A review of behavioral and neuroimaging studies. Neuropsychol Rev. 2010;20(3):290-322. doi:10.1007/s11065-010-9138-6

5. Enticott PG, Kennedy HA, Johnston PJ, Rinehart NJ, Tonge BJ, Taffe JR et al. Emotion recognition of static and dynamic faces in autism spectrum disorder. Cogn Emot. 2014;28(6):1110-8. doi:10.1080/02699931.2013.867832

6. Molnar-Szakacs I, Wang MJ, Laugeson EA, Overy K, Wu WL, Piggot J. Autism, emotion recognition and the mirror neuron system: the case of music. Mcgill J Med. 2009;12(2):87-98.

7. Ramachandran VS, Oberman LM. Broken mirrors: a theory of autism. Sci Am. 2006;295(5):62-9.

8. Palau-Baduell M, Valls-Santasusana A, Salvadó-Salvadó B. Trastornos del espectro autista y ritmo mu: una nueva perspectiva neurofisiológica. Rev Neurol. 2011;52(Supl 1):S141-6.

9. Marques, LJ, Silva-Vernon F, Silva, APRS, Albergaria MB. Padrão de atividade cortical ótima para aprendizagem hábil motriz e cognitiva. Fitness Perform J. 2006;5(3):177-86. doi:10.3900/fpj.5.3.177.p

10. Calomeni MR, Rocha JAMS, Silva APR, Ribeiro LHB, Marques L, Siza MAF et al. Brain stimulation plus an imagery procedure used as biofeedback training for recovery of motor functions deteriorated by stroke: a case study. Arq Neuropiquiatr. 2013;71(3):153-8. doi:10.1590/S0004-282X2013000300006
11. Phan KL, Wager T, Taylor SF, Liberzon I. Functional neuroanatomy of emotion: a meta-analysis of emotion activation studies in PET and fMRI. Neuroimage. 2002;16(2):331-48. doi:10.1006/nimg.2002.1087

12. NAVA AS. Grupanálise em Carne Viva. Rev Portug Grupanálise. 2000 [cited 2011 Apr 10];(2):59-91. Disponível em: http://www. clinicatagide.pt/upload/grupanalise\%20em\%20carne\%20viva.pdf

13. Baron-Cohen S. The extreme male brain theory of autism. Trends Cogn Sci. 2002;6(6):248-54

14. Kilts CD, Egan G, Gideon DA, Ely TD, Hoffman JM. Dissociable neural pathways are involved in the recognition of emotion in static and dynamic facial expressions. Neurolmage. 2003;18(1):156-68. doi:10.1006/nimg.2002.1323

15. Acharya S, Shukla S. Mirror neurons: enigma of the metaphysical modular brain. J Natural Sci Biol Med. 2012;3(2):118-24. doi:10.4103/0976-9668.101878

16. Frith U. Autism: explaining the enigma. Oxford: Blackwell; 1989.

17. Cornelio-Nieto JO. Autismo infantil y neuronas en espejo. Rev Neurología. 2009;48(Suppl 2):S27-9.

18. Carper RA, Moses P, Tigue ZD, Courchesne E. Cerebral lobes in autism: early hyperplasia and abnormal age effects. Neuroimage. 2002;16(4):1038-51. doi:10.1006/nimg.2002.1099

19. Huh GS, Boulanger LM, Du H, Riquelme PA, Brotz TM, Shatz CJ. Functional requirement for class I MHC in CNS development and plasticity. Science. 2000;290(5499):2155-9. doi:10.1126/science.290.5499.2155

20. Zangwill N. Music, autism, and emotion. Front Psycol. 2013;4:890. doi:10.3389/fpsyg. 2013.00890

21. Calomeni MR, Arêas Neto NT, Azevedo JON, Silva Vernon F. Estimulação cerebral e simulação mental de movimentos: efeitos na geração de sinal eletromiográfico. In: Anais do IV Congresso Internacional do Conhecimento Científico; 2012 Sep 19-21; Campos dos Goytacazes: Institutos Superiores de Ensino do Censa; 2012. p. 19-21. 